\title{
Climate Response to Anomalously Large and Small Atlantic Warm Pools during the Summer
}

\author{
ChunZai Wang \\ Physical Oceanography Division, NOAA/Atlantic Oceanographic and Meteorological Laboratory, Miami, Florida \\ SANG-KI LEE \\ Cooperative Institute for Marine and Atmospheric Studies, University of Miami, Miami, Florida \\ DAVID B. ENFIELD \\ Physical Oceanography Division, NOAA/Atlantic Oceanographic and Meteorological Laboratory, Miami, Florida
}

(Manuscript received 7 May 2007, in final form 9 October 2007)

\begin{abstract}
This paper uses the NCAR Community Atmospheric Model to show the influence of Atlantic warm pool (AWP) variability on the summer climate and Atlantic hurricane activity. The model runs show that the climate response to the AWP's heating extends beyond the AWP region to other regions such as the eastern North Pacific. Both the sea level pressure and precipitation display a significant response of low (high) pressure and increased (decreased) rainfall to an anomalously large (small) AWP, in areas with two centers located in the western tropical North Atlantic and in the eastern North Pacific. The rainfall response suggests that an anomalously large (small) AWP suppresses (enhances) the midsummer drought, a phenomenon with a diminution in rainfall during July and August in the region around Central America. In response to the pressure changes, the easterly Caribbean low-level jet is weakened (strengthened), as is its westward moisture transport. An anomalously large (small) AWP weakens (strengthens) the southerly Great Plains low-level jet, which results in reduced (enhanced) northward moisture transport from the Gulf of Mexico to the United States east of the Rocky Mountains and thus decreases (increases) the summer rainfall over the central United States, in agreement with observations. An anomalously large (small) AWP also reduces (enhances) the tropospheric vertical wind shear in the main hurricane development region and increases (decreases) the moist static instability of the troposphere, both of which favor (disfavor) the intensification of tropical storms into major hurricanes. Since the climate response to the North Atlantic SST anomalies is primarily forced at low latitudes, this study implies that reduced (enhanced) rainfall over North America and increased (decreased) hurricane activity due to the warm (cool) phase of the Atlantic multidecadal oscillation may be partly due to the AWP-induced changes of the northward moisture transport and the vertical wind shear and moist static instability associated with more frequent large (small) summer warm pools.
\end{abstract}

\section{Introduction}

The Atlantic warm pool (AWP), as part of the Western Hemisphere warm pool (WHWP; Wang and Enfield 2001, 2003), is a large body of warm water comprising the Gulf of Mexico, the Caribbean Sea, and the western tropical North Atlantic. The AWP has a large

Corresponding author address: Dr. Chunzai Wang, Physical Oceanography Division, NOAA/AOML, 4301 Rickenbacker Causeway, Miami, FL 33149.

E-mail: chunzai.wang@noaa.gov seasonal cycle, and the fluctuations of its area show a large anomalous variation, with large warm pools being almost three times larger than small ones (Wang et al. 2006). Using various datasets, Wang et al. (2006) show observational evidence of the anomalous AWP's influences on Western Hemisphere summer rainfall and Atlantic hurricane activity (summer here always refers to the boreal summer). In particular, they find a negative correlation between the anomalous AWP area index and rainfall anomalies in the central United States and a positive correlation between the AWP index and Atlantic hurricanes. Then, Wang and Lee (2007) and 
Wang et al. (2007) use the National Center for Atmospheric Research (NCAR) Community Atmospheric Model, version 3 (CAM3) to investigate and examine the impact of the climatological mean AWP (i.e., annual or normal AWP) on the summer climate of the Western Hemisphere. The model experiments show that the effects of the annual AWP are to 1) weaken the summer North Atlantic subtropical high (NASH); 2) strengthen the summer continental low over the North American monsoon region; 3) reduce the easterly $\mathrm{Ca}$ ribbean low-level jet (CLLJ) and its westward moisture transport; 4) weaken the southerly Great Plains lowlevel jet (GPLLJ) and change GPLLJ's northward moisture transport; and 5) reduce the tropospheric vertical wind shear in the main hurricane development region and increase the moist static instability of the troposphere, both of which are believed to favor the hurricane formation and development during the Atlantic hurricane season.

A natural and interesting question to ask is what these model results of the annual AWP may imply for interannual or longer time-scale fluctuations of the AWP. The present paper extends the modeling work of Wang and Lee (2007) and Wang et al. (2007) by examining the influence of anomalously large-small AWPs on the summer climate of the Western Hemisphere and Atlantic hurricane activity. Section 2 describes the model experiment designs in this study. Section 3 shows the response of sea level pressure (SLP) and precipitation to AWP variability. Section 4 documents the response of the CLLJ's and GPLLJ's moisture transports. Section 5 demonstrates the AWP's response related to Atlantic hurricane activity, and section 6 shows the atmospheric response to the whole WHWP that also includes the eastern North Pacific warm pool. Finally, section 7 provides a discussion and summary.

\section{Model experiment designs}

The atmospheric general circulation model used in this study is the latest version (v3.1) of the NCAR CAM3. It is a global spectral model with a triangular spectral truncation of the spherical harmonics at zonal wavenumber 42 (T42), which roughly gives a $2.8^{\circ}$ latitude by $2.8^{\circ}$ longitude horizontal resolution. It is vertically divided into 26 hybrid sigma-pressure layers: the upper regions of the atmosphere are gridded by pressure while sigma coordinate system is used for the lower levels and a hybrid coordinate system is used in the middle layers. See Collins et al. (2006) for more detailed explanations about the physical parameterizations of CAM3, and Hurrell et al. (2006) and Deser et al. (2006) for the model's performances for the seasonal variations and interannual variability.

Monthly SST from the Hadley Centre Sea Ice and SST dataset (HadISST) on a $1^{\circ}$ latitude by $1^{\circ}$ longitude resolution (Rayner et al. 2003) is used to force CAM3. Using the HadISST, we calculate the anomalous AWP index that is defined as the area anomalies of SST warmer than $28.5^{\circ} \mathrm{C}$ during July-October. A warm pool $33 \%$ larger (smaller) than the climatological warm pool area is identified as a large (small) warm pool; otherwise, warm pools are classified as normal or neutral. From 1949-2001, there are six large warm pools (1952, 1958, 1969, 1987, 1995, 1998) and seven small warm pools $(1971,1974,1975,1976,1984,1986,1992)$. Almost all of the large (small) AWP years are during the warm (cool) phases of the Atlantic Multidecadal Oscillation (AMO; note that the large AWP in 1987 is associated with the AMO cool phase of 1970-90). That is, warm (cool) phases of the AMO are populated by more frequent large (small) AWPs (Wang et al. 2006). Based on these years for large and small warm pools, we make SST composites for large and small warm pools.

We first conduct three sets of ensemble model simulations: control (CTRL), large AWP (LAWP), and small AWP (SAWP). In the CTRL run, CAM3 is globally forced by the monthly climatological SST. In the LAWP run, the 12-monthly SSTs for the large AWP composites are used in the AWP region (from $5^{\circ}$ to $30^{\circ} \mathrm{N}$ between $40^{\circ} \mathrm{W}$ and the coast of the Americas) for forcing CAM3, while the monthly HadISST climatology is specified for the rest of the global ocean. In the set of the SAWP simulation, CAM3 is forced by the small AWP monthly SST composites in the AWP region and climatological SST elsewhere. To prevent discontinuity of SST forcing around the edges of the AWP box, a mask of weights is applied near the AWP boundary. The smoothing is applied to five model grids centered at the AWP boundary, with respective weights of $1.0,0.75,0.50,0.25$, and 0.0 from the inside to the outside model grids of the AWP boundary. The SST forcing differences between the LAWP and CTRL runs and between the SAWP and CTRL runs are shown in Figs. 1a-d. The largest positive SST anomalies can reach above $0.6^{\circ} \mathrm{C}$ during the summer (Fig. 1a). Although the positive and negative SST anomalies are not exactly symmetric, both the large and small AWPs show a large SST variation in the summer and fall (Figs. 1b,d).

For each set of simulations the model is integrated for $20 \mathrm{yr}$. The first two years of output are discarded to exclude any possible transient spinup effects. A time mean is then calculated by averaging together the output for the remaining $18 \mathrm{yr}$ over the three-month period 
(a) LAWP - CTRL (JJA)

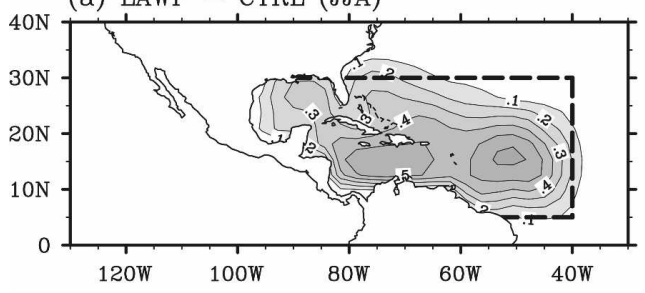

(c) SAWP - CTRL (JJA)

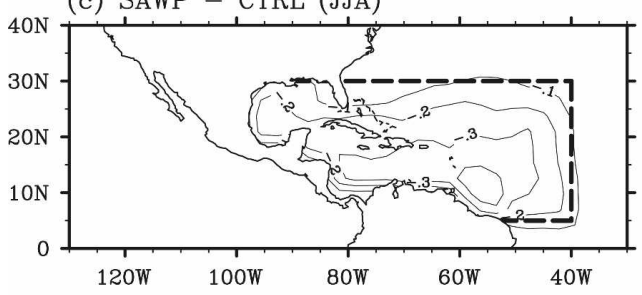

(e) LWHWP - CTRL (JJA)

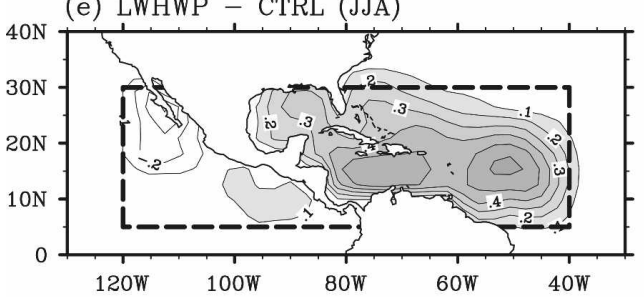

(g) SWHWP - CTRL (JJA)

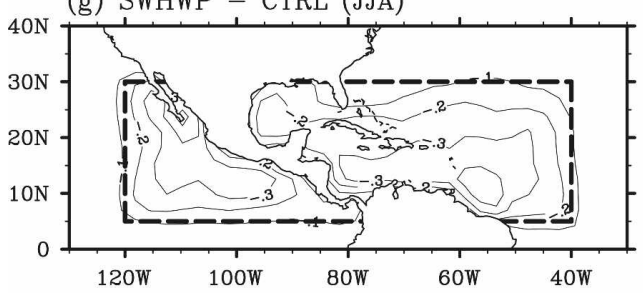

(b) LAWP - CTRL

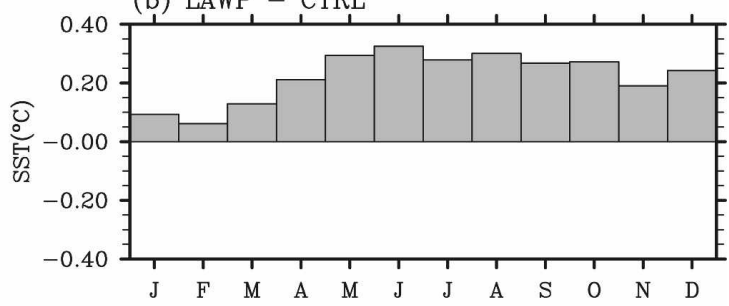

(d) SAWP - CTRL
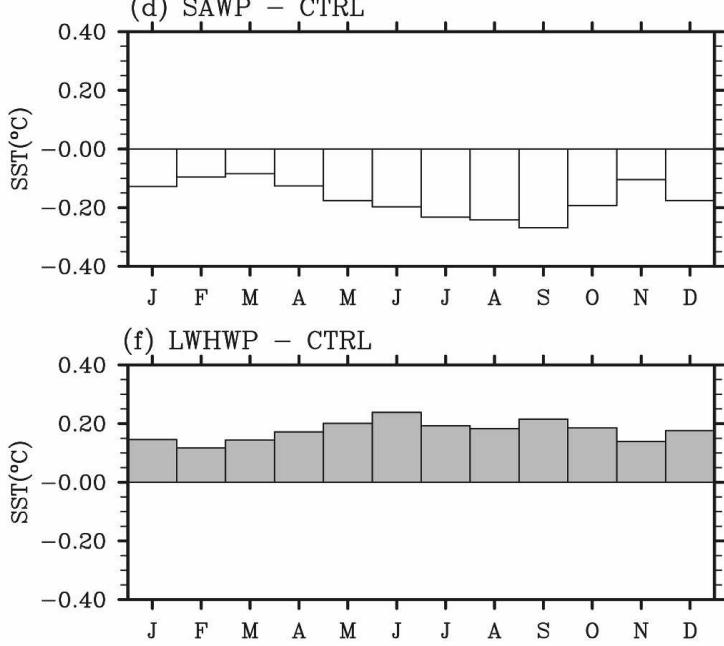

(h) SWHWP - CTRL

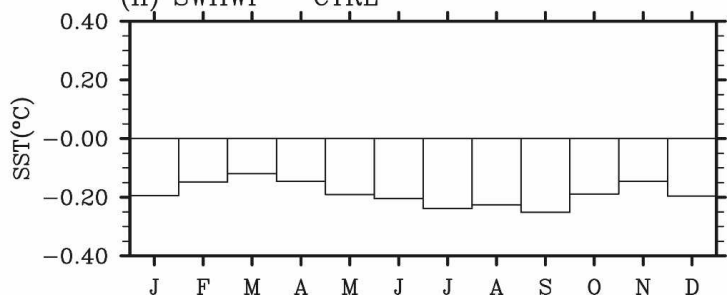

FIG. 1. SST $\left({ }^{\circ} \mathrm{C}\right)$ forcing differences. Shown are (a) SST difference between the LAWP and CTRL runs during JJA, (b) seasonal variation of the SST difference between the LAWP and CTRL runs, (c) SST difference between the SAWP and CTRL runs during JJA, (d) seasonal variation of the SST difference between the SAWP and CTRL runs, (e) SST difference between the LWHWP and CTRL runs during JJA, (f) seasonal variation of the SST difference between the LWHWP and CTRL runs, (g) SST difference between the SWHWP and CTRL runs during JJA, and (h) seasonal variation of the SST difference between the SWHWP and CTRL runs. In contour panels, the SST difference larger than $0.1^{\circ} \mathrm{C}$ is shaded and the zero contour is not plotted. The contour interval is $0.1^{\circ} \mathrm{C}$. The AWP and the WHWP boxes are marked.

of June-August (JJA). We focus on JJA because we are interested in summertime climate response to the anomalous AWP. In the hurricane section (section 5), our analyses will be focused on the six-month period of June-November (JJASON) since the official Atlantic hurricane season is from 1 June to 30 November. Assuming that each year is statistically independent, this is equivalent to an ensemble mean with 18 members. To clearly examine the effect of the anomalous AWP, the difference is taken between the LAWP and SAWP runs (LAWP minus SAWP).
The whole WHWP also includes the eastern North Pacific west of Central America. To see whether or not the eastern North Pacific warm pool affects the results presented in this paper, we perform two additional model experiments: large WHWP (LWHWP) and small WHWP (SWHWP). The SST forcing composites of these two model runs are similar to those of the LAWP and SAWP, except in the eastern North Pacific (from $5^{\circ}$ to $30^{\circ} \mathrm{N}$ between $120^{\circ} \mathrm{W}$ and the coast of the Americas) where the SST composites for large and small warm pools are used (instead of the climatologi- 
SLP (JJA)

(a) CTRL

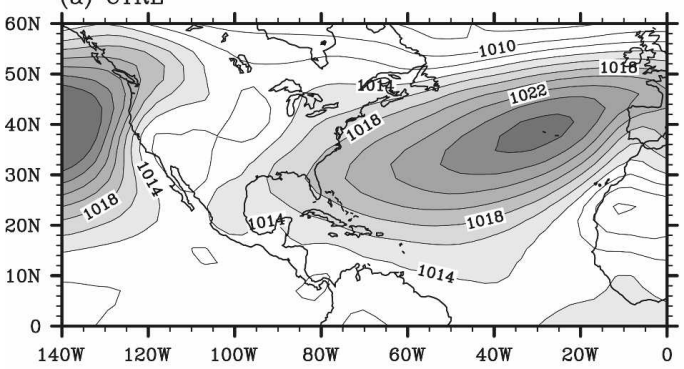

(c) LAWP - SAWP

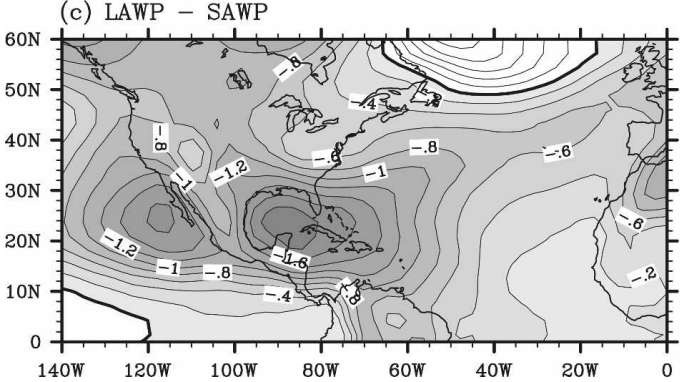

Precipitation (JJA)

(b) CTRL

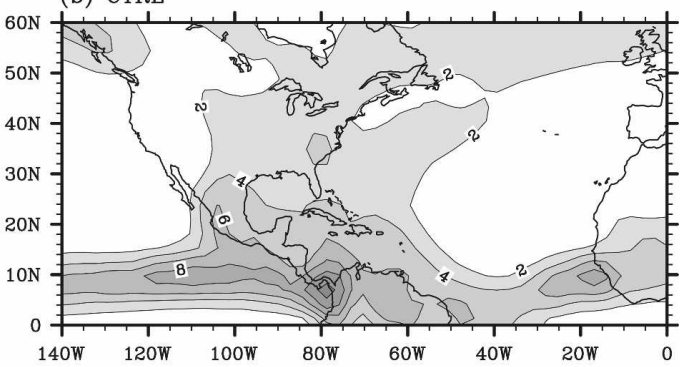

(d) LAWP - SAWP

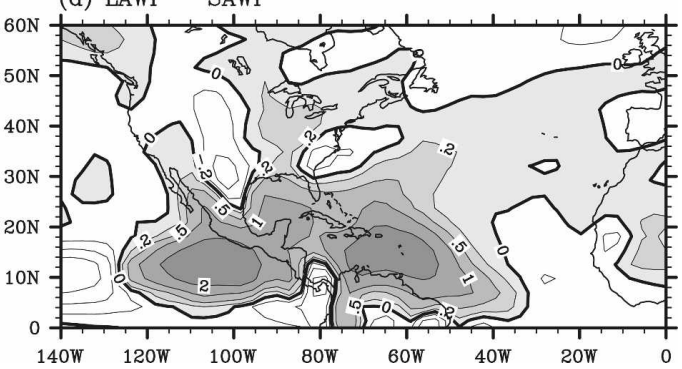

FIG. 2. (left) SLP (mb) and (right) precipitation $\left(\mathrm{mm} \mathrm{day}^{-1}\right)$ from the CAM3 ensemble runs during JJA. Shown are (a) SLP from the CTRL run (SLP higher than $1014 \mathrm{mb}$ is shaded with a contour interval of $2 \mathrm{mb}$ ), (b) precipitation from the CTRL run (rainfall larger than $2 \mathrm{~mm}_{\text {day }}{ }^{-1}$ is shaded with a contour interval of $2 \mathrm{~mm}$ day $^{-1}$ ), (c) SLP difference between the LAWP and SAWP runs (negative SLP difference is shaded with a contour interval of $0.2 \mathrm{mb}$ ), and (d) precipitation difference between the LAWP and SAWP runs. In (d), the positive rainfall difference is shaded and the contour lines are plotted at $-4.0,-2.0,-1.0,-0.5,-0.2,0.0,0.2,0.5,1.0,2.0$, and $4.0 \mathrm{~mm} \mathrm{day}^{-1}$.

cal SSTs as in the LAWP and SAWP runs). The SST forcing differences between the LWHWP and CTRL runs and between the SWHWP and CTRL runs are shown in Figs. 1e-h. When the AWP is anomalously warm, the eastern North Pacific is not warm (Fig. 1e). However, the cool AWP is associated with the cooling of the eastern North Pacific (Fig. 1g).

Wang et al. (2007) already compare the CAM3 model simulation with the National Centers for Environmental Prediction (NCEP)-NCAR reanalysis field and the precipitation product of the Climate Prediction Center (CPC) Merged Analysis of Precipitation (CMAP). For most of the simulated variables, CAM3 does a reasonably good job. In addition, we also perform an Atmospheric Model Intercomparison Project (AMIP)-type integration by forcing CAM3 from 1950 2001 (using the HadISST global SST). We then calculate the regression of the SLP anomalies during the summer onto the AWP area index and then compare it with the NCEP-NCAR reanalysis field. The CAM3 simulation displays a similar pattern to that of the NCEP-NCAR reanalysis, confirming its capability to simulate the AWP-related variability. In this paper, we thus will not show model's comparisons with observational data. Here we will mainly focus on the CAM3 modeled climate response to the large and small AWPs and the associated mechanisms.

\section{Response of SLP and precipitation}

The distributions of the simulated SLP and precipitation from the CTRL run during the summer (JJA) are shown in Figs. 2a,b. As stated in Wang et al. (2007), CAM3 does a reasonably good job in comparison with the NCEP-NCAR reanalysis and the CMAP rainfall. In the summer, the North Atlantic and Pacific subtropical highs reside in the eastern subtropical oceans where the ocean temperature is relatively cool (Fig. 2a). Sandwiched between two subtropical highs is the continental low over North America, owing to the summertime continental heating. Heavy rainfall is located in the regions of the eastern Pacific and Atlantic intertropical convergence zones (ITCZs) where the air is ascended and temperature is high (Fig. 2b). Other summertime rainy features are over northern South America, Central America, the AWP region, the United States east of the Rocky Mountains, the U.S. Gulf Coast, and the U.S. southeastern seaboard. The western region of the United States, the Pacific seaboard, and the subtropical high regions see less rainfall during the summer. 
The response of SLP and precipitation to LAWPSAWP during the summer is shown in Figs. 2c,d. Both the SLP and precipitation differences show two maximum centers located in the western tropical North Atlantic and in the eastern North Pacific. The close association between the largest precipitation and SLP anomalies suggests that anomalous latent heat release is likely to be forcing the SLP (and hence circulation) anomalies, consistent with the theory of Gill (1980). Recall that there are no SST anomalies in the model forcing of the LAWP and SAWP runs in the eastern Pacific, and the model forced SST anomalies are limited to the AWP region (Figs. 1a,c). However, the model response extends beyond the AWP region to the eastern Pacific. This is because the atmospheric response to the AWP SST forcing is primarily governed by Rossby waves that propagate westward into the eastern North Pacific. Once Rossby wave signals reach the eastern North Pacific, their interaction with the climatological eastern Pacific ITCZ enhances the response there. Thus, the atmospheric response to the AWP's heating shows a large value of low SLP in the eastern North Pacific in addition to the local response near the AWP region. Figure $2 c$ shows that the SLP responses also extend northeastward to Europe and northwestward to North America, suggesting a teleconnection effect of the AWP.

Figure $2 \mathrm{~d}$ shows a negative AWP-induced rainfall anomaly in the region of the GPLLJ and a positive rainfall anomaly from the middle of the Great Plains to the region south of the Great Lakes (TennesseeKentucky-Ohio). The decrease of rainfall in the GPLLJ zone is consistent with the AWP-induced decrease of northward moisture transport associated with the southerly GPLLJ (see section 4). The decrease of rainfall east of Rocky Mountains is also in agreement with observations of Wang et al. (2006) who show a negative correlation between the AWP index and rainfall anomalies in the central United States. The increase of rainfall in the eastern United States may reflect that the AWP is responsible for a large amount of precipitable water over the regions of the AWP and the eastern United States (Wang et al. 2007), and it is also consistent with the westward moisture transport from the Atlantic seaboard to the eastern United States (see section 4).

The positive rainfall anomalies in the eastern North Pacific and Central America in Fig. 2d may be tied to the midsummer drought (MSD), a phenomenon with a diminution in rainfall during July and August in the region around Central America (e.g., Magaña et al. 1999; Mapes et al. 2005; Small et al. 2007). An anomalously large (small) AWP decreases (increases) SLP in the MSD region (Fig. 2c) that induces westerly (easterly) wind anomalies across Central America. The large (small) AWP-induced atmospheric circulation pattern increases (decreases) rainfall in the MSD region, and thus suppresses (enhances) the MSD phenomenon, consistent with the MSD's remote forcing hypothesis of Small et al. (2007). We will further discuss the relationship between AWP variability and the MSD in section 7.

Consistent with Wang et al. (2007), we find that the AWP-induced precipitation anomaly is largely determined by the atmospheric moisture convergence although evaporation also contributes to rainfall. The moisture convergence response to LAWP-SAWP can be further divided into three contributions by 1) the wind change, 2) the specific humidity change, and 3) the product of the wind and specific humidity changes (see section 4 for the separation). Of these three components, the moisture convergence contributed by the wind change is a dominant term (not shown). That is, the effect of AWP variability is to affect atmospheric circulation pattern that changes the atmospheric moisture convergence and thus induces the rainfall change as shown in Fig. 2 d.

\section{Response of CLLJ's and GPLLJ's moisture transports}

The easterly trade winds carry moisture from the tropical North Atlantic Ocean into the Caribbean Sea where the flow intensifies, forming the CLLJ. As the CLLJ transits the Caribbean Sea, it then splits into two branches: one turning northward via the Gulf of Mexico to merge with the southerly GPLLJ, and the other continuing westward across Central America into the eastern North Pacific. Since these jets can bring copious moisture for rainfall, it is thus important for us to examine how the CLLJ's and GPLLJ's moisture transports respond to AWP variability.

\section{a. CLLJ's moisture transport}

The model simulated zonal moisture transport of $q u$ (where $q$ is specific humidity and $u$ is zonal wind) at $75^{\circ} \mathrm{W}$ during the summer is shown in Fig. 3. A strong westward moisture transport associated with the easterly CLLJ is located around $15^{\circ} \mathrm{N}$ at the lower troposphere (Fig. 3a). The $q u$ response to LAWP-SAWP is a positive anomaly of the zonal moisture transport near the CLLJ's transport core (Fig. 3b). This indicates that an anomalously large (small) AWP weakens (strengthens) the CLLJ's westward moisture transport. Figure $3 \mathrm{~b}$ also shows a negative anomaly of the zonal moisture 
Zonal Moisture Transport at $75^{\circ} \mathrm{W}$ (JJA)
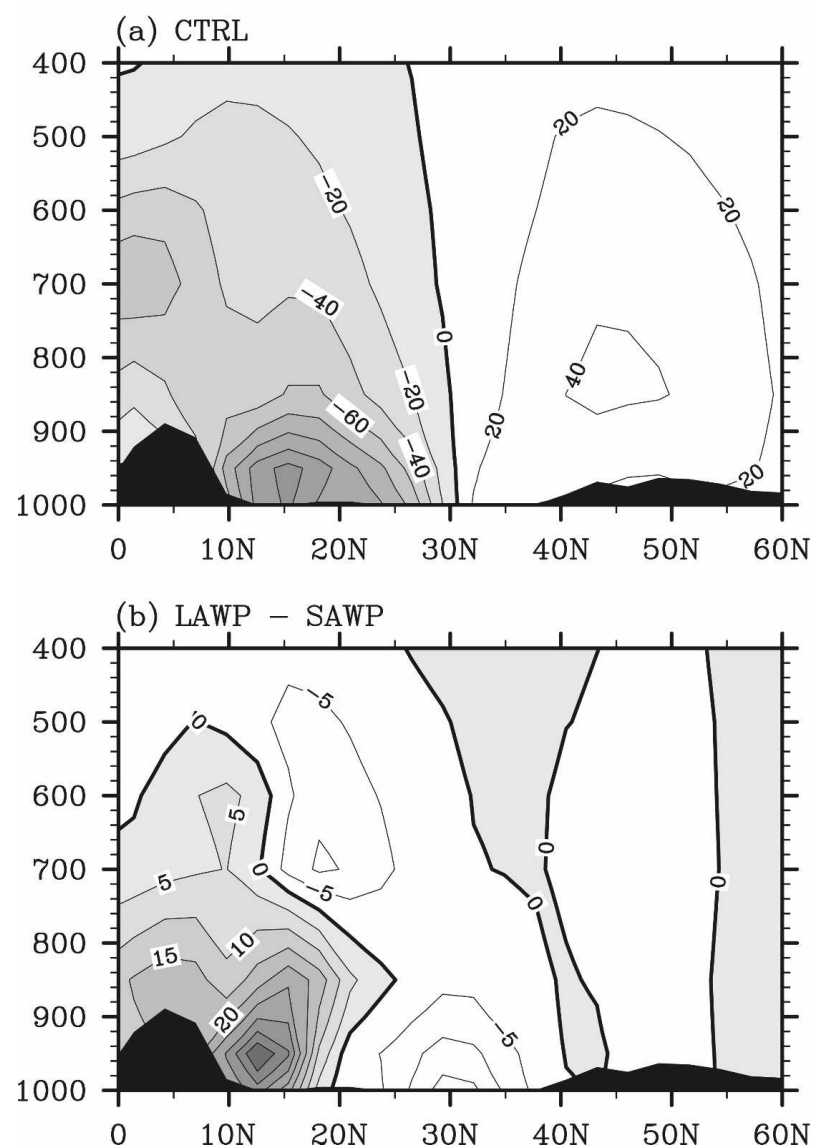

FIG. 3. Meridional-vertical sections of the zonal moisture transport of $q u\left(\mathrm{~g} \mathrm{~kg}^{-1} \mathrm{~m} \mathrm{~s}^{-1}\right)$ at $75^{\circ} \mathrm{W}$ during JJA from (a) the CTRL ensemble run and (b) the difference between the LAWP and SAWP runs. In (a), the westward moisture transport is shaded and the contour interval is $20 \mathrm{~g} \mathrm{~kg}^{-1} \mathrm{~m} \mathrm{~s}^{-1}$. In (b), the positive moisture transport difference is shaded and the contour interval is $5 \mathrm{~g} \mathrm{~kg}^{-1} \mathrm{~m} \mathrm{~s}^{-1}$. The moisture transports are calculated directly during the model integration at every time step ( $20 \mathrm{~min})$ by using the model output of $q$ and $u$. The unit on the vertical axis is mb.

transport at $30^{\circ} \mathrm{N}$ near the surface. This westward moisture transport anomaly from the southeastern United States seaboard is consistent with the positive rainfall anomaly in the eastern United States as shown in Fig. 2d.

The zonal moisture transport is a product of the specific humidity and zonal wind. What is the most important factor for determining the moisture transport response to LAWP-SAWP shown in Fig. 3b? To answer this question, we let $\Delta q=q_{\mathrm{LAWP}}-q_{\mathrm{SAWP}}$ and $\Delta u=$ $u_{\text {LAWP }}-u_{\text {SAWP. }}$ The zonal moisture transport response in Fig. $3 \mathrm{~b}$ can then be separated into three components contributed by 1) the zonal wind change $q_{\mathrm{SAWP}} \Delta u, 2$ ) the specific humidity change $u_{\mathrm{SAWP}} \Delta q$, and 3 ) the prod- uct of the zonal wind and specific humidity changes $\Delta u \Delta q$. Figure 4 shows the contribution of these three terms. The CLLJ's moisture transport response to LAWP-SAWP is mainly attributed to $q_{\mathrm{SAWP}} \Delta u$, whereas $u_{\mathrm{SAWP}} \Delta q$ is small and $\Delta u \Delta q$ is negligible. In other words, an anomalously large (small) AWP reduces (enhances) the easterly CLLJ which then results in a decrease (increase) of the westward moisture transport. Note that the reduction (enhancement) of the easterly CLLJ is consistent with Fig. 2c showing a low SLP centered in the AWP region that produces westerly wind anomalies in the Caribbean. The westward flow at $30^{\circ} \mathrm{N}$ in Fig. $4 \mathrm{a}$ is also due to the AWP-induced low SLP pattern of Fig. 2c that produces easterly wind anomalies north of the low SLP center.

The effect of the anomalously large AWP on the CLLJ's westward moisture transport is similar to that of the annual AWP (Wang et al. 2007). The common physical reason for the reduction of the CLLJ's westward moisture transport is that the AWP weakens the $\mathrm{NASH}$, especially at its southwestern edge. The NASH produces the easterly trade winds in the tropical North Atlantic that form the easterly CLLJ when they enter into the Caribbean Sea. Observations show that the CLLJ varies with the Caribbean SLP as well as with the meridional SST and SLP gradients in the CLLJ region (Wang 2007), which is expected from the geostrophic balance. When the AWP is warm (cold), the SLP in the Caribbean Sea is low (high). The low (high) SLP, associated with small (large) meridional SLP gradients, corresponds to a weakening (strengthening) of the CLLJ and thus the CLLJ's moisture transport.

\section{b. GPLLJ's moisture transport}

The GPLLJ's meridional moisture transport from the CTRL run and its response to LAWP-SAWP at $30^{\circ} \mathrm{N}$ during the summer are shown in Fig. 5. A strong northward moisture transport is located along the eastern slopes of the Sierra Madre Oriental range (Fig. 5a). This summertime northward moisture transport provides a moisture source for rainfall over the Great Plains of the central United States where rainfall is observed to reach maximum during the summer (e.g., Mo and Berbery 2004; Mo et al. 2005; Ruiz-Barradas and Nigam 2005; Nigam and Ruiz-Barradas 2006). Figure $5 \mathrm{~b}$ shows a negative value of moisture transport difference near the GPLLJ's transport core, in response to LAWP-SAWP. This means that an anomalously large (small) AWP reduces (enhances) the GPLLJ's northward moisture transport. The reduction (enhancement) of the GPLLJ's northward moisture transport is associated with a decreased (increased) rainfall in the 
Zonal Moisture Transport at $75^{\circ} \mathrm{W}$ (JJA)
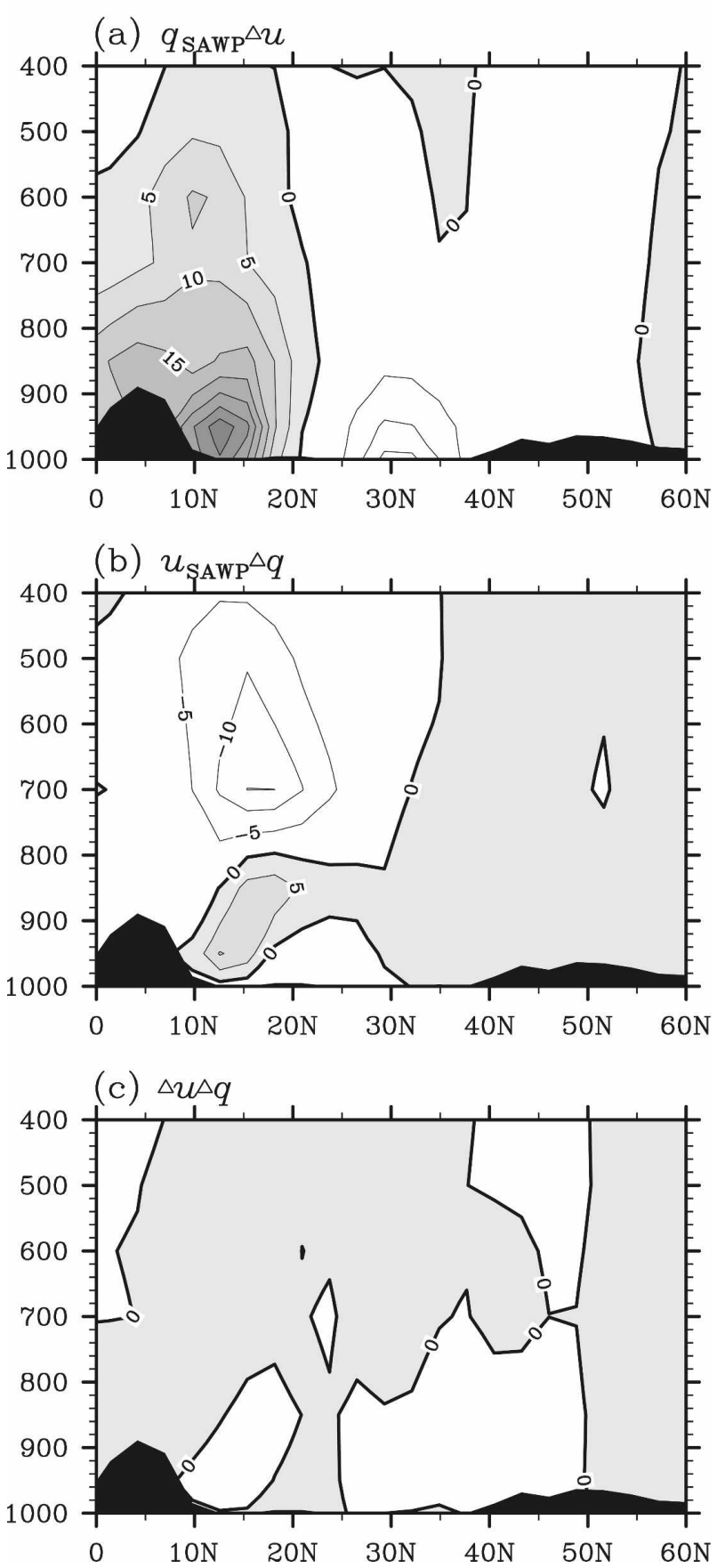

FIG. 4. Zonal moisture transport difference $\left(\mathrm{g} \mathrm{kg}^{-1} \mathrm{~m} \mathrm{~s}^{-1}\right)$ between the LAWP and SAWP runs at $75^{\circ} \mathrm{W}$ during JJA contributed by (a) the zonal wind change $q_{\mathrm{SAWP}} \Delta u$, (b) the specific humidity change $u_{\mathrm{SAWP}} \Delta q$, and (c) the product of the zonal wind and specific humidity changes $\Delta u \Delta q$ (where $\Delta u=u_{\text {LAWP }}-u_{\text {SAWP }}$ and $\left.\Delta q=q_{\text {LAWP }}-q_{\text {SAWP }}\right)$. The positive moisture transport difference is shaded and the contour interval is $5 \mathrm{~g} \mathrm{~kg}^{-1} \mathrm{~m} \mathrm{~s}^{-1}$. The unit on the vertical axis is mb.
Merid. Moisture Transport at $30^{\circ} \mathrm{N}$ (JJA)
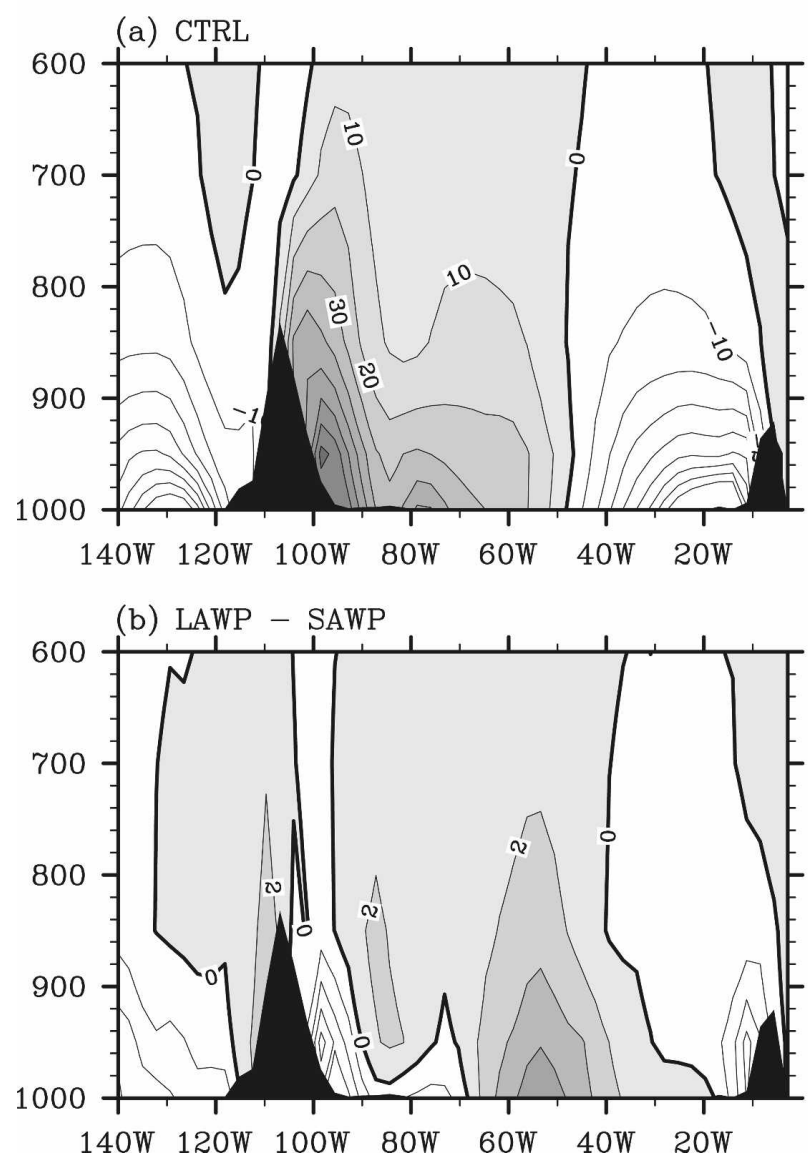

FIG. 5. Zonal-vertical sections of the meridional moisture transport of $q v\left(\mathrm{~g} \mathrm{~kg}^{-1} \mathrm{~m} \mathrm{~s}^{-1}\right)$ at $30^{\circ} \mathrm{N}$ during JJA from (a) the CTRL ensemble run and (b) the difference between the LAWP and SAWP runs. In (a), the northward moisture transport is shaded and the contour interval is $10 \mathrm{~g} \mathrm{~kg}^{-1} \mathrm{~m} \mathrm{~s}^{-1}$. In (b), the positive moisture transport difference is shaded and the contour interval is $2 \mathrm{~g} \mathrm{~kg}^{-1} \mathrm{~m} \mathrm{~s}^{-1}$. The moisture transports are calculated directly during the model integration at every time step ( $20 \mathrm{~min}$ ) by using the model output of $q$ and $v$. The unit on the vertical axis is mb.

United States east of the Rocky Mountains, as shown in Fig. 2d. The model result is consistent with observations of Wang et al. (2006) who found a negative correlation between the AWP index and rainfall anomalies in the central United States, and is also consistent with the results of Ruiz-Barradas and Nigam (2005) and MestasNuñez et al. (2007).

Again, we can divide the meridional moisture transport through $30^{\circ} \mathrm{N}$ into three components contributed by 1 ) the meridional wind change $q_{\mathrm{SAwP}} \Delta v, 2$ ) the specific humidity change $v_{\mathrm{SAWP}} \Delta q$, and 3 ) the product of the zonal wind and specific humidity changes $\Delta v \Delta q$. Figure 6 shows that the meridional wind change of $q_{\mathrm{SAWP}} \Delta v$ is a dominant term, and $v_{\mathrm{SAWP}} \Delta q$ and $\Delta v \Delta q$ 
Merid. Moisture Transport at $30^{\circ} \mathrm{N}$ (JJA)
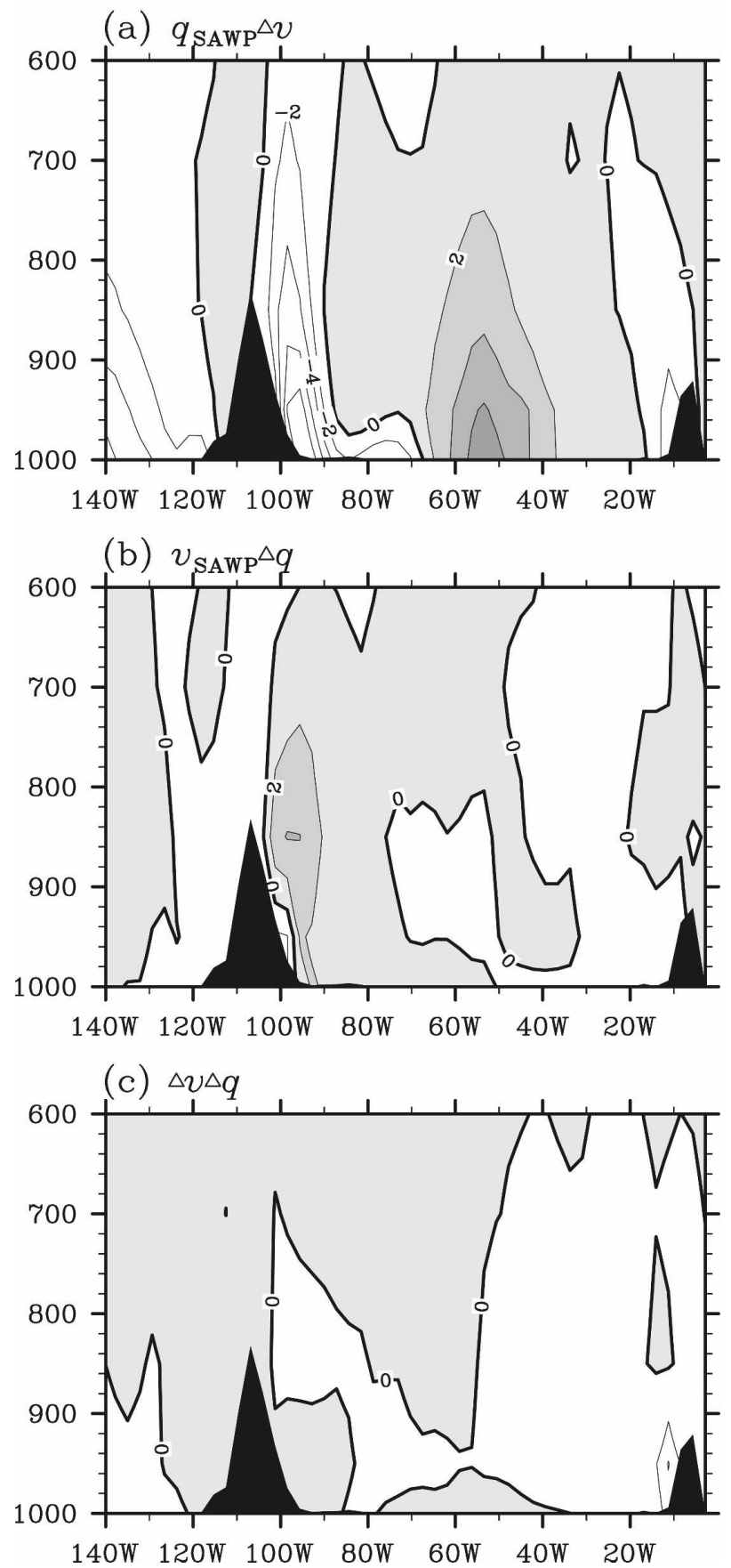

FIG. 6. Meridional moisture transport difference $\left(\mathrm{g} \mathrm{kg}^{-1} \mathrm{~m} \mathrm{~s}^{-1}\right)$ between the LAWP and SAWP runs at $30^{\circ} \mathrm{N}$ during JJA contributed by (a) the meridional wind change $q_{\mathrm{SAWP}} \Delta v$, (b) the specific humidity change $v_{\mathrm{SAWP}} \Delta q$, and (c) the product of the meridional wind and specific humidity changes $\Delta v \Delta q$ (where $\Delta v=v_{\text {LAWP }}-v_{\text {SAWP }}$ and $\Delta q=q_{\text {LAWP }}-q_{\text {SAWP }}$ ). The positive moisture transport difference is shaded and the contour interval is $2 \mathrm{~g} \mathrm{~kg}^{-1} \mathrm{~m} \mathrm{~s}^{-1}$. The unit on the vertical axis is $\mathrm{mb}$. are small. This indicates that an anomalously large (small) AWP reduces (enhances) the southerly GPLLJ which then decreases (increases) the northward moisture transport to the central United States. This finding is again consistent with that of Wang et al. (2006) who observe that when the AWP is anomalously large (small), the near-surface wind anomalies over the central and southeastern United States are southward (northward). It is the AWP-induced change of the southerly GPLLJ (and the wind near the GPLLJ) that contributes to the inverse relationship between the AWP SST and rainfall anomalies in the central United States.

As shown in Wang et al. (2007), the effect of the annual AWP is also to reduce the southerly GPLLJ during the summer. However, the annual AWP has an opposite effect on the summer GPLLJ's northward moisture transport; that is, the annual AWP's impact is to enhance the northward moisture transport to the central United States in the summer. This is because the annual AWP induces a large increase of specific humidity (see Fig. 11b of Wang et al. 2007) east of the Rocky Mountains that contributes to the increase of the northward moisture transport. The moisture transport increase due to specific humidity change overcomes the decrease owing to the weakening of the southerly GPLLJ, resulting in a net increase of the northward moisture transport during the summer. However, for the case of the anomalous AWP presented in this paper, AWP variability has little effect on specific humidity change in United States east of the Rocky Mountains (Fig. 6b). The anomalous AWP-induced GPLLJ's moisture transport thus follows the contribution by the weakening of the southerly GPLLJ, being a reduction of the northward moisture transport during the summer. Therefore, the key for the different effects of the annual and anomalous AWPs on the summer northward moisture transport is that the anomalous AWP does not have any influence or it has little influence on specific humidity east of the Rocky Mountains.

What is the possible cause that may produce little influence of an anomalous AWP on specific humidity east of the Rocky Mountains? The AWP region shows a high value of the precipitable water during the summer when the annual AWP is developed (Wang et al. 2007), which serves as a moisture source exporting to the United States for rainfall. Since the annual AWP already exports more moisture to the United States, it seems plausible that less moisture would be available for an anomalously large AWP to transport northward. In other words, the specific humidity change is not sensitive to a further increase of SST associated with an anomalously large AWP since the annual SST in the 
Vertical Wind Shear (JJASON)
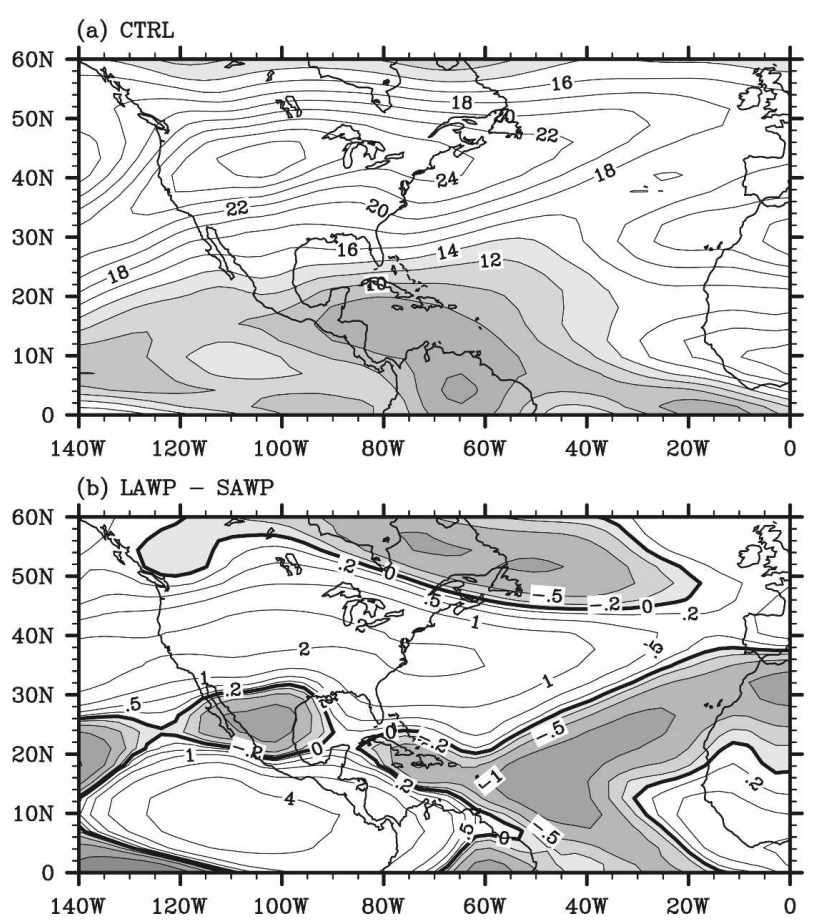

FIG. 7. Tropospheric vertical wind shear $\left\{\left[\left(U_{200}-U_{850}\right)^{2}+\right.\right.$ $\left.\left.\left(V_{200}-V_{850}\right)^{2}\right]^{1 / 2} ; \mathrm{m} \mathrm{s}^{-1}\right\}$ during JJASON from (a) the CTRL ensemble run and (b) the difference between the LAWP and SAWP runs. In (a), the vertical wind shear smaller than $14 \mathrm{~m} \mathrm{~s}^{-1}$ is shaded and the contour interval is $2 \mathrm{~m} \mathrm{~s}^{-1}$. In (b), the negative wind shear difference is shaded and the contour lines are plotted at -4.0 , $-2.0,-1.0,-0.5,-0.2,0.0,0.2,0.5,1.0,2.0$, and $4.0 \mathrm{~m} \mathrm{~s}^{-1}$.

AWP is already high. In addition, the effect of the annual AWP is to weaken the CLLJ and increase moist static instability over the Caribbean and thus increase convective activity and rainfall there, so the atmospheric moisture over the AWP region available for an anomalous AWP to export is decreased. These can result in little change of specific humidity in the United States east of the Rocky Mountains associated with an anomalously large or small AWP.

\section{Response related to Atlantic hurricanes}

There are many parameters that can influence and control the development and formation of tropical storms (e.g., Gray 1979). Here we focus on the dynamical parameter of the tropospheric vertical wind shear and the thermodynamical parameter of the moist static instability of the troposphere. The vertical wind shear from the CTRL run and its response to LAWP - SAWP during the Atlantic hurricane season of JJASON are shown in Fig. 7. The climatological wind shear during JJASON shows a relatively low value in the tropical
North Atlantic, the Caribbean Sea, and northern South America (Fig. 7a). The wind shear response to anomalous AWPs shows that most of the main development region for Atlantic hurricanes (between $10^{\circ}$ and $20^{\circ} \mathrm{N}$ and from Central America to West Africa) is covered by negative anomalies of vertical shear (Fig. 7b). The average reduction of the vertical wind shear is about $-0.9 \mathrm{~m} \mathrm{~s}^{-1}$ over the region of $10^{\circ}-20^{\circ} \mathrm{N}, 70^{\circ}-30^{\circ} \mathrm{W}$. This indicates that an anomalously large (small) AWP reduces (enhances) the vertical wind shear in the tropical North Atlantic and the Caribbean Sea. The model result is consistent with the observational data of Wang et al. (2006) who show significant correlations among the anomalous AWP index, the tropospheric vertical wind shear in the main development region, and Atlantic hurricanes. Another feature in Fig. $7 b$ is that an anomalously large AWP induces a large increase of the vertical wind shear in the eastern North Pacific. This AWP-induced increase of wind shear in the eastern North Pacific may hinder the development and formation of tropical cyclones in the eastern Pacific.

The AWP-induced vertical wind shear is further examined by the response of the geopotential height and wind at 200 and $850 \mathrm{mb}$ to LAWP-SAWP, as shown in Fig. 8. Consistent with Gill's (1980) dynamics, the atmospheric response to the AWP's heating is baroclinic. The lower troposphere shows a cyclonic circulation in the AWP and eastern North Pacific, whereas the upper troposphere displays an anticyclonic circulation pattern. In the tropical North Atlantic, the mean circulation features the easterly trade winds in the lower troposphere and the westerly winds in the upper troposphere. Thus, the AWP-induced anomalous cyclonic and anticyclonic circulation patterns reduce both the lower-tropospheric easterly winds and the uppertropospheric westerly winds, resulting in a reduction of the vertical wind shear. In the eastern North Pacific, the mean zonal circulation is relatively weak, owing to the presence of the eastern Pacific ITCZ. The AWPinduced baroclinic wind patterns in the eastern North Pacific in Fig. 8 thus increase the vertical wind shear there.

Convective available potential energy (CAPE), which is a measure of the moist static instability of the troposphere, represents the amount of buoyant energy available to accelerate a parcel vertically, or the amount of work a parcel does on the environment. CAPE is especially important when air parcels are able to reach the layer of free convection. The higher the CAPE value, the more energy available to foster storm growth (or for an easterly wave to become a tropical storm). CAPE provides the fuel for moist convection, 
Geopotential Height \& Wind (JJASON)

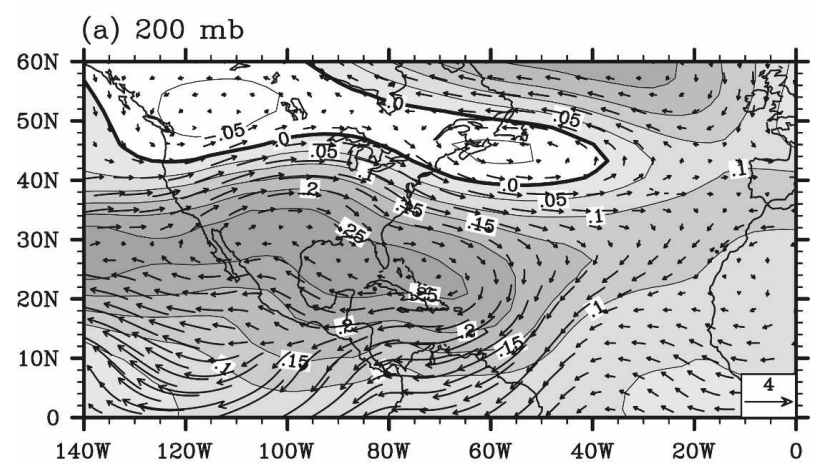

(b) $850 \mathrm{mb}$

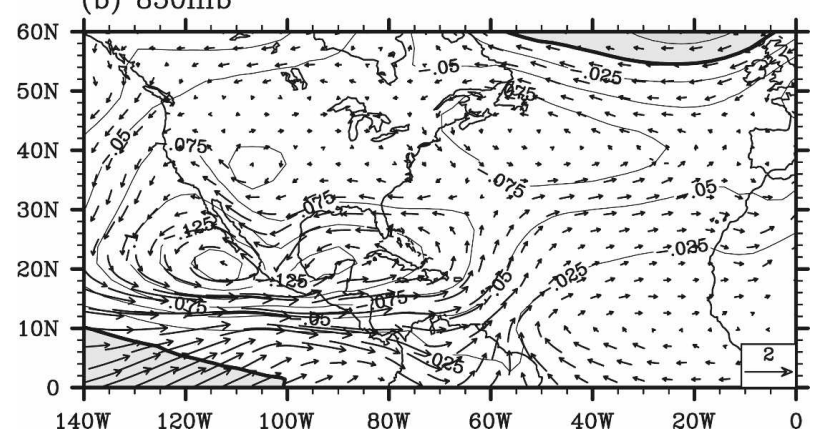

FIG. 8. Geopotential height $\left(10^{2} \mathrm{~m}\right)$ and wind $\left(\mathrm{m} \mathrm{s}^{-1}\right)$ difference between the LAWP and SAWP runs during JJASON at (a) 200 and (b) $850 \mathrm{mb}$. The positive geopotential height difference is shaded and the contour interval is $0.025 \times 10^{2} \mathrm{~m}$.

thus it also is a potential indicator of hurricane intensity (Emanuel 1994). Figure 9 shows the CAPE from the CTRL run and its response to LAWP-SAWP during the Atlantic hurricane season of JJASON. During the hurricane season, the climatological mean CAPE shows large values over the Caribbean Sea and Pacific and Atlantic ITCZ regions (Fig. 9a) owing to warm nearsurface air temperature and large water vapor content in these regions. The CAPE response to LAWPSAWP is a large positive value in the tropical North Atlantic (Fig. 9b). That is, an anomalously large (small) AWP tends to increase (decrease) CAPE because of the increased (decreased) near-surface air temperature and water vapor content. More specifically, once the warm and moist (cold and dry) surface air parcel is lifted to the level of free convection, the air parcel gains large (small) buoyancy, thus we expect strong (weak) and more (less) frequent moist convections that favor (disfavor) hurricane development.

The southeast-to-northwest orientation of the positive CAPE anomaly lies along the track of many historical storms with disastrous landfall in the United States, Hurricanes Hugo in 1989 and Andrew in 1992 being more notable examples. Such storms typically de-
CAPE (JJASON)

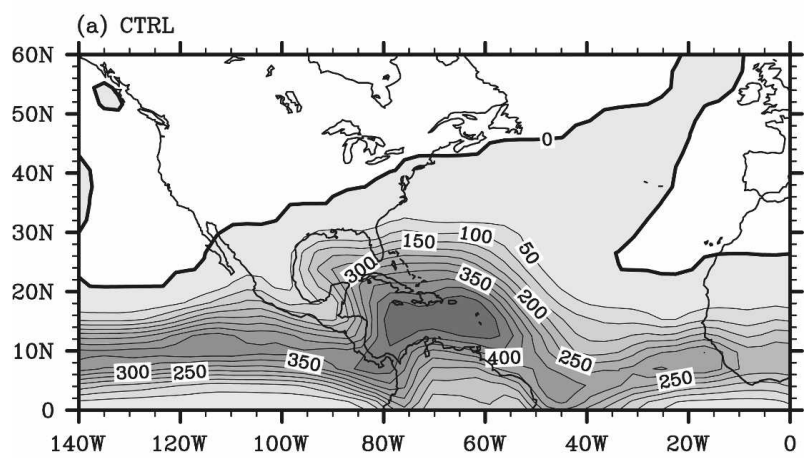

(b) LAWP - SAWP

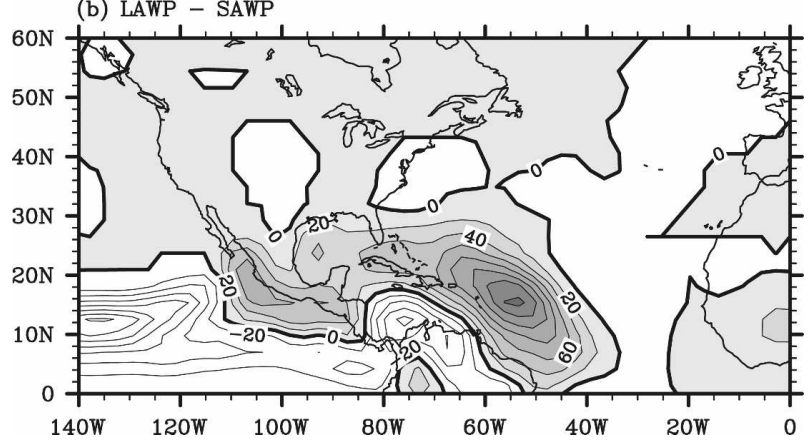

FIG. 9. CAPE $\left(\mathrm{J} \mathrm{kg}^{-1}\right)$ during JJASON from (a) the CTRL ensemble run and (b) the difference between the LAWP and SAWP runs. The positive values are shaded. The contour intervals in (a) and (b) are 50 and $20 \mathrm{~J} \mathrm{~kg}^{-1}$, respectively.

velop from easterly waves off Africa during AugustSeptember. In contrast, the model response indicates a decrease in CAPE over the western Caribbean, a region in which storms tend to form during the early and late portions of the hurricane season. Both features could be of consequence for Florida, the target for many landfalling hurricanes. The tracks of many hurricanes that hit Florida pass through regions in or just north of these anomalies (additional information is available online at www.hurricanecity.com/hebertbox.htm).

In summary, our model runs show that an anomalously large (small) AWP makes both the vertical wind shear and the moist static instability more (less) favorable for hurricane development from tropical storms that form off Africa and thus increases (decreases) Atlantic hurricane activity. Tropical storms that form in the Caribbean may encounter a mixed environment for shear and moist static instability.

\section{Response to the whole WHWP}

We also perform two additional model experiments in which CAM3 is forced by the SST composites for large and small warm pools over the region of the 


\section{LWHWP - SWHWP}

(a) SLP

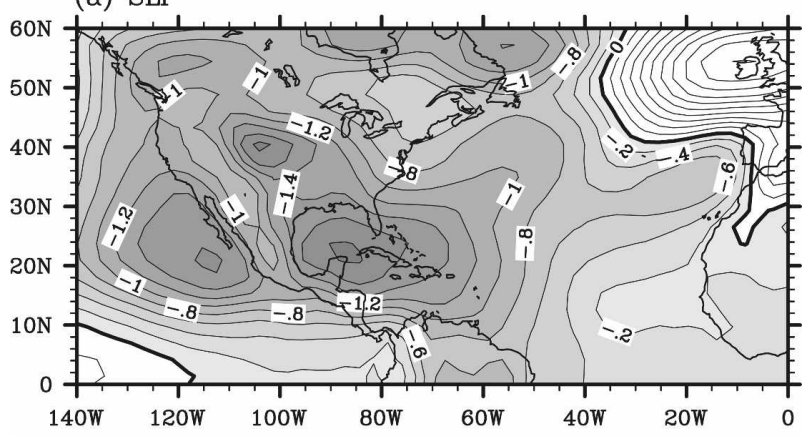

(b) Precipitation

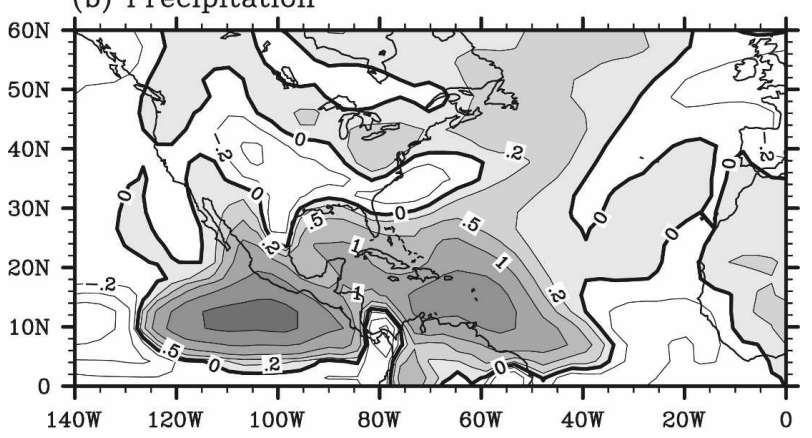

(c) Vertical Wind Shear

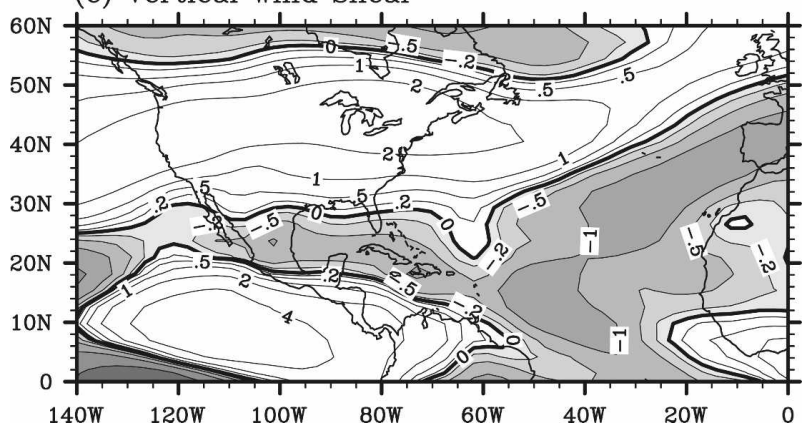

FIG. 10. SLP (mb), precipitation $\left(\mathrm{mm} \mathrm{day}^{-1}\right)$, and vertical wind shear $\left(\mathrm{m} \mathrm{s}^{-1}\right)$ differences between the LWHWP and SWHWP runs. Shown are (a) SLP difference during JJA, (b) precipitation difference during JJA, and (c) vertical wind shear difference during JJASON. In (a), the negative SLP difference is shaded and the contour interval is $0.2 \mathrm{mb}$. In (b), the positive rainfall difference is shaded and the contour lines are plotted at $-4.0,-2.0,-1.0$, $-0.5,-0.2,0.0,0.2,0.5,1.0,2.0$, and $4.0 \mathrm{~mm} \mathrm{day}^{-1}$. In (c), the negative wind shear difference is shaded and the contour lines are plotted at $-4.0,-2.0,-1.0,-0.5,-0.2,0.0,0.2,0.5,1.0,2.0$, and $4.0 \mathrm{~m} \mathrm{~s}^{-1}$.

whole WHWP (i.e., SST variability in the region of both the AWP and the eastern North Pacific warm pool). Our model runs show that the inclusion of the eastern North Pacific warm pool does not change the results presented in sections 3-5. As an example, Fig. 10 shows the SLP, precipitation, and vertical wind shear response to LWHWP-SWHWP. Comparison with Figs.
$2 \mathrm{c}, \mathrm{d}$ and $7 \mathrm{~b}$ shows that the atmospheric response to the AWP's heating is not sensitive to the presence of the eastern North Pacific warm pool. However, there are some minor differences between the model response of LWHWP-SWHWP and LAWP-SAWP. The positive rainfall anomaly in the eastern Pacific for LWHWPSWHWP is larger than that for LAWP-SAWP since the local SST anomalies in the eastern North Pacific may help enhance the rainfall response there. A close inspection of Figs. 10c and $7 \mathrm{~b}$ shows that the eastern North Pacific warm pool enhances the reduction of the vertical wind shear in the regions of the Caribbean and the Gulf of Mexico. Another feature is that the presence of the eastern North Pacific warm pool extends the negative rainfall anomaly region (near the GPLLJ) eastward to the southeastern United States (Fig. 10b).

\section{Discussion and summary}

The AWP shows both the seasonal and interannual variability (Wang and Enfield 2001, 2003) and its area index also displays longer time-scale variations such as that of the Atlantic Multidecadal Oscillation (AMO; Wang et al. 2006). Using NCAR CAM3, Wang and Lee (2007) and Wang et al. (2007) demonstrate the impact of the annual AWP on the summer climate of the Western Hemisphere and Atlantic hurricanes, whereas the present paper shows the anomalously large-small AWP's influences. The model experiments show that the annual and anomalous AWPs have a similar effect on the summer climate and hurricanes except for the influence on the summertime GPLLJ's northward moisture transport to the central United States. The key for the AWP's influence on climate is through the AWP-induced SLP distribution. Consistent with Gill's (1980) theory, the atmospheric response to the AWP's heating is atmospheric Rossby waves with low SLP to the northwest of the heating. Once Rossby wave signals reach the eastern Pacific, their interaction with the ITCZ in the eastern Pacific enhances the SLP response there. Therefore, in response to the AWP's heating, the atmosphere shows a large value of low SLP in the eastern Pacific in addition to the local low SLP centered near the AWP region. That is, the effect of the AWP in the summer is to weaken the North Atlantic subtropical high (NASH), especially at its southwestern edge, and to strengthen the continental low over the North American monsoon region. What this study shows is that a larger (smaller) than normal AWP increases (decreases) that response, as expected, with similar effects on the low-level jets that deliver moisture to the eastern Pacific and North America, and with similar effects on 
the development of hurricanes that form over the tropical North Atlantic.

Associated with two low SLP centers are two maximum positive precipitation anomalies located near the AWP region and in the eastern North Pacific. The close association between the largest precipitation and SLP anomalies suggests that anomalous latent heat release is likely to be forcing the SLP and circulation anomalies. Although both the annual and anomalous AWPs show a low SLP response in the eastern North Pacific, the amplitude of the SLP response in the eastern Pacific for the anomalous AWP is larger than that for the annual AWP. This may reflect that an anomalously large AWP excites Rossby waves more easily than the annual AWP, reaching the eastern Pacific where the Rossby wave signals interact with the eastern Pacific ITCZ for enhancing the SLP response there. Our studies suggest that tropical North Atlantic SST (or the AWP) can also affect the eastern Pacific, in counterpoint to the conventional notion that tropical Pacific SST influences the tropical North Atlantic (e.g., Enfield and Mayer 1997; Huang et al. 2002). This is consistent with a highresolution regional model study by Xie et al. (2007) who find that an Atlantic cooling results in anomalous easterlies in the eastern Pacific and cooling in the equatorial eastern Pacific. The implication is that there is a two-way process between the tropical Pacific and Atlantic or they interact with each other or that they act in succession, that is, the Pacific on the Atlantic during the winter, and vice versa in the summer.

Our atmospheric model results show that an anomalously large AWP weakens the NASH that in turn weakens the northeast trade wind at NASH's southwestern side. In nature, there may be a positive oceanatmosphere feedback involved the NASH. On one hand, a large or warm AWP weakens the NASH and then the northeast trade winds. On the other hand, the weakening of the trade winds may increase SST in the AWP region and thus the AWP becomes larger. This issue needs to be addressed by a coupled ocean-atmosphere model.

The effect of both the annual and anomalously large AWP is to weaken the easterly CLLJ, which then contributes to a reduction of the CLLJ's westward moisture transport. The physics for the reduction is also that the AWP weakens the NASH. When the AWP is warm (cold), the SLP in the Caribbean Sea associated with the weakening of the NASH is low (high). The low (high) SLP, accompanied by a small (large) meridional SLP gradient, corresponds to a weakening (strengthening) of the CLLJ and thus a decrease in the CLLJ's westward moisture transport.
The CAM3 runs show that both the annual and anomalously large AWPs reduce the southerly GPLLJ during the summer. However, the annual and anomalous AWPs have a different effect on the summer GPLLJ's northward moisture transport to the central United States: the annual AWP's impact is to enhance the northward moisture transport, and the anomalously large AWP reduces the northward moisture transport. The annual AWP induces a large increase of specific humidity east of the Rocky Mountains, which contributes to the increase of the northward moisture transport. The moisture transport increase due to specific humidity change overcomes that of the weakening of the southerly GPLLJ, resulting in an increase of the northward moisture transport during the summer. However, the anomalous AWP has little effect on specific humidity change in United States east of the Rocky Mountains. The anomalously large AWPinduced GPLLJ's moisture transport follows the contribution by the weakening of the southerly GPLLJ, being a reduction of the northward moisture transport during the summer.

Consistent with the reduction of the northward moisture transport to the central United States, our model runs show that an anomalously large (small) AWP corresponds to decreased (increased) rainfall in the United States east of the Rocky Mountains. The model result is consistent with or confirms the observational result of Wang et al. (2006) who show a negative correlation between the AWP index and rainfall anomalies in the central United States. Thus, we can conclude that an anomalously large (small) AWP can decrease (increase) rainfall in the central United States through the mechanism of the reduced (enhanced) northward moisture transport from the AWP region to the United States.

The results in this paper suggest that AWP variability may also affect the midsummer drought (MSD), a phenomenon with a diminution in rainfall during July and August in southern Mexico and Central America (e.g., Magaña et al. 1999; Mapes et al. 2005; Small et al. 2007). Small et al. (2007) show that the MSD is associated with a low-level anticyclone centered in the southern Gulf of Mexico that produces easterly wind anomalies across Central America (their Fig. 7c). The easterly wind anomalies are accompanied by subsidence and divergence over the Central American region, giving rise to the MSD. Our model result (Fig. 8) indicates that a small (large) AWP produces a low-level anticyclone (cyclone) in the region of the AWP and eastern North Pacific that induces easterly (westerly) wind anomalies across Central America. This suggests that a small 
(large) AWP enhances (suppresses) the MSD. Indeed, our Fig. 2d does show a decrease (increase) of rainfall in the MSD region for a small (large) AWP.

Both the annual and anomalous AWPs make the vertical wind shear and the moist static instability more favorable for Atlantic hurricanes to develop over the tropical North Atlantic. This is broadly consistent with the observational results of Wang et al. (2006), while the dominance of large (small) AWPs during the warm (cool) phase of the AMO is consistent with Goldenberg et al. (2001). Dynamically, the AWP-induced atmospheric circulation pattern is baroclinic (Gill 1980), with a large warm pool producing a cyclone in the lower troposphere and an anticyclone in the upper troposphere. This anomalous circulation structure reduces the lower-tropospheric easterly flow and the uppertropospheric westerly flow, resulting in a reduction of the vertical wind shear that favors atmospheric convection. Thermodynamically, the AWP increases CAPE, which provides the fuel for moist convection. However, the locations of maxima in the reduction of the vertical wind shear and the increase of CAPE are different for the annual and anomalous AWPs. The maxima for the annual AWP are located near the Caribbean Sea, whereas the maxima for the anomalous AWP are in the western tropical North Atlantic. The eastward shift of the maxima for the anomalous AWP may be a response to the anomalous latent heating of the atmosphere implied by the eastward shift of the precipitation in the case of the anomalous AWP. This may also provide an explanation of the southeastward shift for the genesis location of tropical cyclones (e.g., Kossin and Vimont 2007).

Enfield et al. (2001) show that the AMO in North Atlantic SST is inversely correlated with rainfall over most regions of the United States, and McCabe et al. (2004) show that the AMO was probably involved in past megadroughts. As shown in Wang et al. (2006), the summer AWP area index also shows the signal of the AMO, while in this study we see that almost all of the upper (lower) tercile warm pools are associated with warm (cool) phases of the AMO (section 2). A longterm SST data over the past 153 yr (1854-2006) confirms this result (Wang et al. 2008). Thus, warm (cool) phases of the AMO are characterized by repeated large (small) summer AWPs, the cumulative effects of which can amount to persistent drought (pluvial) during the growing season. On interannual and longer time scales, even subtle but sustained changes in the moisture inflow to the U.S. Great Plains from the Gulf of Mexico can contribute to severe drought conditions, as caused by subtle tropical Pacific SST change (e.g., Schubert et al. 2004; Seager 2007). Sutton and Hodson (2007) show that the climate response to the AMO SST anomalies is primarily forced by the tropical Atlantic SST anomalies. This seems to suggest that mechanisms of the AMO-related (or North Atlantic SST-related) rainfall over North America and Atlantic hurricane activity may be operated through the AWP-induced mechanisms: the northward moisture transport for rainfall, and the vertical wind shear and moist static instability for hurricanes. In other words, the AWP acts as a link between the AMO and rainfall in North America and Atlantic hurricane activity.

The paper establishes the AWP as an important mechanism by which Atlantic SSTs influence Western Hemisphere climate during the summer. Climate phenomena such as El Niño-Southern Oscillation, the North Atlantic Oscillation, and the AMO can act on or interact with the AWP on interannual to multidecadal time scales and in that way achieve their influence on the summer climate. Clearly, there is a need for a further investigation of the AWP. Such work may include 1) investigating the reproducibility of our results in other atmospheric models, 2) examining the AWP's influence based on coupled ocean-atmosphere-land models, and 3) exploring the AWP's impact on climate and hurricanes under global warming scenarios.

Acknowledgments. We thank the reviewers and editor for their comments and suggestions. This work was supported by a grant from National Oceanic and Atmospheric Administration (NOAA) Climate Program Office and by the base funding of NOAA Atlantic Oceanographic and Meteorological Laboratory (AOML). The findings and conclusions in this report are those of the authors and do not necessarily represent the views of the funding agency.

\section{REFERENCES}

Collins, W. D., and Coauthors, 2006: The formulation and atmospheric simulation of the Community Atmosphere Model Version 3 (CAM3). J. Climate, 19, 2144-2161.

Deser, C., A. Capotondi, R. Saravanan, and A. S. Phillips, 2006: Tropical Pacific and Atlantic climate variability in CCSM3. J. Climate, 19, 2451-2481.

Emanuel, K. A., 1994: Atmospheric Convection. Oxford University Press, $580 \mathrm{pp}$.

Enfield, D. B., and D. A. Mayer, 1997: Tropical Atlantic sea surface temperature variability and its relation to El NiñoSouthern Oscillation. J. Geophys. Res., 102, 929-945.

_ A. M. Mestas-Nuñez, and P. J. Trimble, 2001: The Atlantic Multidecadal Oscillation and its relation to rainfall and river flows in the continental U.S. Geophys. Res. Lett., 28, $2077-$ 2080.

Gill, A. E., 1980: Some simple solutions for heat-induced tropical circulation. Quart. J. Roy. Meteor. Soc., 106, 447-462. 
Goldenberg, S. B., C. Landsea, A. M. Mestas-Nuñez, and W. M. Gray, 2001: The recent increase in Atlantic hurricane activity. Science, 293, 474-479.

Gray, W. M., 1979: Hurricanes: Their formation, structure, and likely role in the tropical circulation. Meteorology over the Tropical Oceans, D. B. Shaw, Ed., Royal Meteorological Society, 155-218.

Huang, B., P. S. Schopf, and Z. Pan, 2002: The ENSO effect on the tropical Atlantic variability: A regionally coupled model study. Geophys. Res. Lett., 29, 2039, doi:10.1029/2002GL014872.

Hurrell, J. W., J. J. Hack, A. S. Phillips, J. Caron, and J. Yin, 2006: The dynamical simulation of the Community Atmosphere Model Version 3 (CAM3). J. Climate, 19, 2162-2183.

Kossin, J. P., and D. J. Vimont, 2007: A more general framework for understanding Atlantic hurricane variability and trends. Bull. Amer. Meteor. Soc., 88, 1767-1781.

Magaña, V., J. A. Amador, and S. Medina, 1999: The midsummer drought over Mexico and Central America. J. Climate, 12, 1577-1588.

Mapes, B. E., P. Liu, and N. Buenning, 2005: Indian monsoon onset and the Americas midsummer drought: Out-ofequilibrium responses to smooth seasonal forcing. J. Climate, 18, 1109-1115.

McCabe, G., M. Palecki, and J. Betancourt, 2004: Pacific and Atlantic Ocean influences on multidecadal drought frequency in the United States. Proc. Natl. Acad. Sci. USA, 101, 4136-4141.

Mestas-Nuñez, A. M., D. B. Enfield, and C. Zhang, 2007: Water vapor fluxes over the Intra-Americas Sea: Seasonal and interannual variability and associations with rainfall. J. Climate, 20, 1910-1922.

Mo, K. C., and E. H. Berbery, 2004: Low-level jets and the summer precipitation regimes over North America. J. Geophys. Res., 109, D06117, doi:10.1029/2003JD004106.

_, M. Chelliah, M. L. Carrera, R. W. Higgins, and W. Ebisuzaki, 2005: Atmospheric moisture transport over the United States and Mexico as evaluated in the NCEP regional reanalysis. J. Hydrometeor., 6, 710-728.

Nigam, S., and A. Ruiz-Barradas, 2006: Seasonal hydroclimate variability over North America in global and regional reanalyses and AMIP simulations: Varied representation. J. Climate, 19, 815-837.

Rayner, N. A., D. E. Parker, E. B. Horton, C. K. Folland, L. V.
Alexander, D. P. Powell, E. C. Kent, and A. Kaplan, 2003 Global analyses of sea surface temperature, sea ice, and night marine air temperature since the late nineteenth century. J. Geophys. Res., 108, 4407, doi:10.1029/2002JD002670.

Ruiz-Barradas, A., and S. Nigam, 2005: Warm season rainfall variability over the U.S. Great Plains in observations, NCEP and ERA-40 reanalyses, and NCAR and NASA atmospheric model simulations. J. Climate, 18, 1808-1830.

Schubert, S. D., M. J. Suarez, P. J. Region, R. D. Koster, and J. T. Bacmeister, 2004: On the cause of the 1930s Dust Bowl. Science, 303, 1855-1859.

Seager, R., 2007: The turn of the century drought North American drought: Global context, dynamics, and past analogs. J. Climate, 20, 5527-5552.

Small, R. J. O., S. P. de Szoeke, and S.-P. Xie, 2007: The Central American midsummer drought: Regional aspects and largescale forcing. J. Climate, 20, 4853-4873.

Sutton, R. T., and D. L. R. Hodson, 2007: Climate response to basin-scale warming and cooling of the North Atlantic Ocean. J. Climate, 20, 891-907.

Wang, C., 2007: Variability of the Caribbean low-level jet and its relations to climate. Climate Dyn., 29, 411-422.

— warm pool. Geophys. Res. Lett., 28, 1635-1638.

_, and - 2003: A further study of the tropical Western Hemisphere warm pool. J. Climate, 16, 1476-1493.

_, and S.-K. Lee, 2007: Atlantic warm pool, Caribbean lowlevel jet, and their potential impact on Atlantic hurricanes. Geophys. Res. Lett., 34, L02703, doi:10.1029/2006GL028579.

— D. B. Enfield, S.-K. Lee, and C. W. Landsea, 2006: Influences of the Atlantic warm pool on Western Hemisphere summer rainfall and Atlantic hurricanes. J. Climate, 19, 30113028.

, S.-K. Lee, and D. B. Enfield, 2007: Impact of the Atlantic warm pool on the summer climate of the Western Hemisphere. J. Climate, 20, 5021-5040.

,$- \ldots$, and,- 2008 : Atlantic warm pool acting as a link between Atlantic multidecadal oscillation and Atlantic tropical cyclone activity. Geochem. Geophys. Geosyst., doi:10.1029/2007GL001809, in press.

Xie, S.-P., and Coauthors, 2007: A regional ocean-atmosphere model for eastern Pacific climate: Toward reducing tropical biases. J. Climate, 20, 1504-1522. 